\title{
Electron Microscopic Study on Lysis of a Cyanobacterium Microcystis
}

\author{
Keiko Ozaki, ${ }^{a}$ Emiko Ito, ${ }^{b}$ Saori Tanabe, ${ }^{a}$ Kaori Natsume, ${ }^{a}$ Kiyomi Tsuji, ${ }^{c}$ \\ and Ken-ichi Harada*, $a$
}

${ }^{a}$ Graduate School of Environmental and Human Science, and Faculty of Pharmacy, Meijo University, Yagotoyama 150 Tempaku, Nagoya 468-8503, Japan, ${ }^{b}$ Research Center for Pathogenic Fungi and Microbial Toxicoses, Chiba University, Inohana 1-8-1 Chuoku, Chiba 260-8673, Japan and ${ }^{c}$ Kanagawa Prefectural Institute of Public Health, Shimomachiya, Shimomachiya 1-3-1 Chigasaki, Kanagawa 253-0087, Japan

(Received March 13, 2009; Accepted May 28, 2009; Published online June 5, 2009)

In a previous study, it was suggested that $\beta$-cyclocitral plays an important role in understanding the lysis of cyanobacteria under natural conditions. The present study was conducted in order to understand how the $\beta$ cyclocitral lyses cyanobacterial cells, and other anticyanobacterial agents were also investigated. The preliminary study using a scanning electron microscope (SEM) demonstrated that there were three types of morphological changes in the cyanobacterial cells when they were incubated with anticyanobacterial agents: volatile compounds from cyanobacteria cause shrinking and then wrinkling; terpenoids contact directly and cause stripping; basic amino acids cause swelling and then collapsing. In order to clarify the extreme difference in the damage during the morphological changes between the $\beta$-cyclocitral and L-lysine (Lys), the transmission electron microscope (TEM) technique was applied. Although a definite difference in the morphological damage was observed, a plausible mechanism for $\beta$-cyclocitral could be not deduced. Throughout the experiments using antibiotics, it was found that the apparent morphological changes after lysis did not always correspond to the mode of action.

Key words — cyanobacteria, scanning electron microscope, transmission electron microscope, morphological change, $\beta$-cyclocitral, L-lysine

\section{INTRODUCTION}

Cyanobacteria (blue-green algae) commonly occur in a variety of water sources throughout the world. A variable, but high proportion of the cyanobacterial blooms and scums, which can be developed annually in lakes, reservoirs, canals and slow-flowing rivers, contain potent toxins. Microcystins, ${ }^{1,2)}$ the cyclic heptapeptide toxins produced by cyanobacteria such as Microcystis, show potent hepatotoxicity and tumor-promoting activities by inhibition of protein phosphatases 1 and $2 \mathrm{~A}^{3,4)}$ Animal poisoning and human health problems associated with the ingestion of or contact with cyanobacterial scums have long been recognized and a toxic incident involving the death of 50 people occurred in Brazil in 1996 due to microcystins in

${ }^{*}$ To whom correspondence should be addressed: Graduate School of Environmental and Human Science and Faculty of Pharmacy, Meijo University, Yagotoyama 150 Tempaku, Nagoya 468-8503, Japan. Tel.: 81-52-839-2720; Fax: 81-52834-8090; E-mail: kiharada@ccmfs.meijo-u.ac.jp the water used for hemodialysis. ${ }^{5,6)}$ Because toxic cyanobacteria containing microcystins threaten human health and life at present, we must establish an effective method for regulating the occurrence of cyanobacteria and their toxic metabolites.

The overall goal of our series of studies is to establish a plant for the biological control of cyanobacteria and their toxic products using immobilized microorganisms that can lyse cyanobacteria and decompose the microcystins. As the first step, we collected water, soil and sediment, and investigated the bacteria active against cyanobacteria and microcystins. ${ }^{7)}$ Although we obtained several microorganisms that could lyse cyanobacteria, this anticyanobacterial activity was not reproducible, and it was difficult to identify the compound responsible for this activity from the most potent bacterium belonging to the genus Bacillus sp. (termed B-6). ${ }^{8}$ In a preceding study, it was found that another active bacterium belonging to Brevibacillus sp. B-1 also did not produce active compounds; instead, some of the volatile compounds, such as 
8-methyl-2-nonanone, $\beta$-cyclocitral and 3-methyl1-butanol, could lyse cyanobacteria. Interestingly, $\beta$-cyclocitral and 3-methyl-1-butanol were induced from cyanobacteria themselves in the presence of the B-1 cells. Furthermore, it was confirmed that $\beta$ ionone, geosmin and 2-methylisoborneol (2-MIB) derived from cyanobacteria and similar volatile compounds, i.e., terpenoids, produced by plants also had a lytic activity. ${ }^{9)}$ Although the minimum inhibitory concentration (MIC) of the cyanobacterial metabolites was relatively high, it was suggested that $\beta$-cyclocitral was associated with a sudden decline in the biomass or the disappearance of cyanobacteria under natural conditions, ${ }^{10)}$ because $\beta$-cyclocitral caused a characteristic color change in the culture solution from green to blue during the lysis process.

To the best of our knowledge, no study has yet been performed on the mode of action for the lysis of cyanobacteria with these volatile compounds. In order to understand precisely the mode of action of these volatile compounds, particularly $\beta$-cyclocitral, we focused our study on the morphological changes in the cyanobacteria caused by the volatile compounds using an electron microscope in this study. Additionally, the effects of amino acids, such as lysine and arginine, and several antibiotics whose mode of actions against pathogenic bacteria are well understood were also investigated.

\section{MATERIALS AND METHODS}

Chemicals $-\beta$-Cyclocitral, $\beta$-ionone, perillaldehyde, linalool, $\beta$-cyano-L-alanine and colistin sulfate salt were obtained from Sigma-Aldrich (St. Louis, MO, U.S.A.), while ceftazidime, gentamicin sulfate, ofloxacin, geosmin and 2-MIB were purchased from Wako Pure Chemical Industries (Osaka, Japan). D-Arginine, D, L-histidine and acetone were purchased from Nacalai Tesque (Kyoto, Japan). L-Lysine (Lys) was obtained from Kyowa Hakko Kogyo (Tokyo, Japan).

Cyanobacteria - Axenic strains of Microcystis, NIES-102 and NIES-298, were obtained from the National Institute for Environmental Studies (NIES), Tsukuba, Japan. These strains were cultured in 11 Erlenmeyer flasks, each containing a modified MA medium $(300 \mathrm{ml})^{11)}$ at $25^{\circ} \mathrm{C}$ for 8 days under $28 \mu \mathrm{Em}^{-2} \mathrm{~s}^{-1}$ continuous illumination. The MA medium consisted of a mixture of bicine $(500 \mathrm{mg}) ; \mathrm{Ca}\left(\mathrm{NO}_{3}\right)_{2} \cdot 4 \mathrm{H}_{2} \mathrm{O}(50 \mathrm{mg}) ; \mathrm{KNO}_{3}$
(100 mg); $\quad \mathrm{NaNO}_{3} \quad$ (50 mg); $\quad \mathrm{Na}_{2} \mathrm{SO}_{4} \quad$ (40 mg); $\mathrm{MgCl}_{2} \cdot 6 \mathrm{H}_{2} \mathrm{O} \quad(50 \mathrm{mg}) ; \quad \beta$-Na 2 glycerophosphate $(100 \mathrm{mg})$; a metal mixture solution ( $1 \mathrm{ml}$; composed of $1 \mathrm{mg}$ of $\mathrm{Na}_{2}$ EDTA, $0.1 \mathrm{mg}$ of $\mathrm{FeCl}_{3} \cdot 6 \mathrm{H}_{2} \mathrm{O}$, $1 \mathrm{mg}$ of $\mathrm{MnCl}_{3} \cdot 4 \mathrm{H}_{2} \mathrm{O}, 0.1 \mathrm{mg}$ of $\mathrm{ZnCl}_{2}, 1 \mathrm{mg}$ of $\mathrm{CoCl}_{2} \cdot 6 \mathrm{H}_{2} \mathrm{O}, 0.16 \mathrm{mg}$ of $\mathrm{Na}_{2} \mathrm{MoO}_{4} \cdot 2 \mathrm{H}_{2} \mathrm{O}$ and $4 \mathrm{mg}$ of $\mathrm{H}_{3} \mathrm{BO}_{3}$ in $200 \mathrm{ml}$ of distilled water), and the resulting solution was adjusted to $\mathrm{pH}$ 8.6.

Measurement of Anticyanobacterial Activity — The anticyanobacterial activity was determined by measuring the absorbance of chlorophyll-a. ${ }^{12)}$ The final concentration was determined according to the MIC. ${ }^{9)}$ Briefly, each final concentration of the tested anticyanobacterial compound was added to $100 \mathrm{ml}$ of the cultured cyanobacteria, then incubated at $25^{\circ} \mathrm{C}$ with shaking for 7 days under $28 \mu \mathrm{Em}^{-2} \mathrm{~s}^{-1}$ continuous illumination. Water or methanol $(1 \mathrm{ml})$ was used as the control. Eleven $\mathrm{ml}$ aliquots of the culture medium was withdrawn according to the color change during the first day and then once per day until the seventh day. Ten ml portions of the withdrawn samples were filtered on GF-filters. The cyanobacteria on the filters were soaked in $5 \mathrm{ml}$ of acetone, and the resulting mixture was left overnight at $4^{\circ} \mathrm{C}$ in the dark. A $0.2 \mathrm{ml}$ aliquot of the supernatant was placed in each well of a 96-well microplate (Kartell, Milan, Italy), and the absorbance was measured at $665 \mathrm{~nm}$ using an MPR-A4iII microplate reader $\mathrm{TOSOH}$, Tokyo, Japan). The anticyanobacterial activity was determined as a decrease in the absorbance.

Observation of the Treated Cells Using a Scanning Electron Microscope (SEM) - A cyanobacterium (NIES-102) was incubated for 7 days in the presence of $6.5 \mathrm{mM} \beta$-cyclocitral and $\beta$-ionone, $2 \mathrm{mM}$ perillaldehyde, $3 \mathrm{mM}$ linalool, $0.6 \mathrm{mM}$ geosmin and 2-MIB or $0.6 \mathrm{mM}$ amino acids. Eleven $\mathrm{ml}$ aliquots of the culture medium were withdrawn according to the color change during the first day and then once per day until the seventh day. A $0.5 \mathrm{ml}$ portion of the treated cells was washed twice with an equal volume of $\mathrm{pH} 7.4$ buffer in $0.1 \mathrm{M} \mathrm{PBS}$ and fixed with $4 \%$ para-formaldehyde in the same buffer $(0.5 \mathrm{ml})$. The resulting $2 \%$ para-formaldehyde solution was then washed with pH 7.4 buffer in $0.2 \mathrm{M}$ sodium cacodylate. The cells were dehydrated in graded concentrations of ethanol from $50 \%$ to $100 \%$, dried using a critical point drier (HCP-2, Hitachi, Tokyo, Japan), and then finally sputter-coated with platinum-palladium (Hitachi E-102). These specimens were then observed by SEM (Hitachi S-800). 
Effect of Antibiotics on Lysis of Cyanobacteria — The anticyanobacterial activity was measured by an antibiotic at the final concentration of $0.2 \mathrm{mM}$ ceftazidime, $0.3 \mathrm{mM}$ colistin sulfate salt, $0.05 \mathrm{mM}$ gentamicin sulfate, and $0.1 \mathrm{mM}$ ofloxacin. Observation of the Treated Cells Using a Transmission Electron Microscope (TEM) A cyanobacterium (NIES-102) was incubated for $47 \mathrm{hr}$ in the presence of $\beta$-cyclocitral or Lys at the concentration of $6.5 \mathrm{mM}$ and $0.6 \mathrm{mM}$, respectively. The treated cells at $4{ }^{\circ} \mathrm{C}$ were fixed with $2 \%$ glutaraldehyde, buffered at $\mathrm{pH} 7.4$ in $0.1 \mathrm{M}$ sodium cacodylate, then post-fixed with $2 \% \mathrm{OsO}_{4}$ in the same cacodylate buffer, dehydrated with stepwise increments of ethanol concentrations from $50 \%$ to $100 \%$, and embedded in Epon 812. Ultrathin sections were prepared $(t=80-90 \mathrm{~nm})$ using a Super NOVA (Reichert-J, Vienna, Austria), stained with uranyl acetate and lead citrate, each for $15 \mathrm{~min}$, and then examined using a JEM1200EX electron microscope (JEOL, Tokyo, Japan) operated at $100 \mathrm{kV}$.

\section{RESULTS AND DISCUSSION}

\section{Observation of the Morphological Change in Lysed Microcystis with Volatile Cyanobacterial Metabolites and Terpenoids Using a SEM}

At the MIC concentration $(2.5 \mathrm{mM}), \beta$-ionone, geosmin and 2-MIB showed almost the same lytic behavior in that the color of the lysed solution gradually changed from green through yellow-green to a white milky suspension, and $\beta$-cyclocitral provided the characteristic blue color before the appearance of the final white milky suspension.9) The morphological changes in the $\beta$-cyclocitral, $\beta$ ionone, geosmin and 2-MIB were continuously observed for $96 \mathrm{hr}$ using the SEM. Figure 1 shows the typical scanning electron micrographs of the lysed cyanobacterial cells with these cyanobacterial metabolites. The morphological changes with $\beta$-cyclocitral in which the cells initially shrank and then gradually became wrinkled were almost the same as that of the others. The different color changes in the culture broths did not seem to reflect the morphological changes.

Several terpenoids that are volatile and have physicochemical properties similar to those of the cyanobacterial metabolites were examined, and it was found that they lysed the cyanobacteria more rapidly than did the cyanobacterial metabolites. They showed individual color changes in the culture broths. ${ }^{9)}$ The lytic behavior with perillaldehyde and linalool was carefully observed at the concentration of 2 and $3 \mathrm{mM}$, respectively, using the same experimental conditions, and the typical scanning electron micrographs of the lysed cyanobacterial cells are shown in Fig. 2. The morphological change may be due to direct contact and sequential stripping of the surface of the cells, and this behavior was different from that of the cyanobacterial metabolites as shown in Fig. 1. This may be reflected in their mode of action against pathogenic microorganisms, in which they disrupt the permeability barrier of

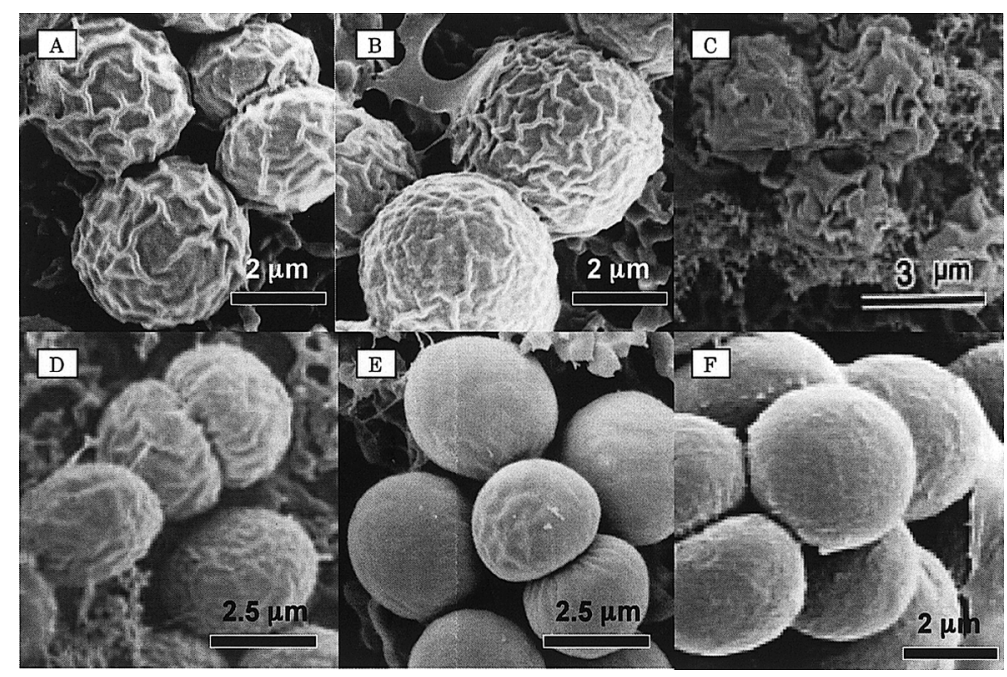

Fig. 1. Scanning Electron Micrographs of Lysed NIES-102 with Volatile Compounds

(A) $\beta$-cyclocitral $(6.5 \mathrm{mM}, 1 \mathrm{hr}),(\mathrm{B}) \beta$-ionone $(6.5 \mathrm{mM}, 0.5 \mathrm{hr})$, (C) geosmin $(0.6 \mathrm{mM}, 0.5 \mathrm{hr})$ and (D) 2-MIB $(0.6 \mathrm{mM}, 96 \mathrm{hr})$. Water (E) (58 hr) and methanol (F) ( $96 \mathrm{hr}$ ) were used as the negative control. 


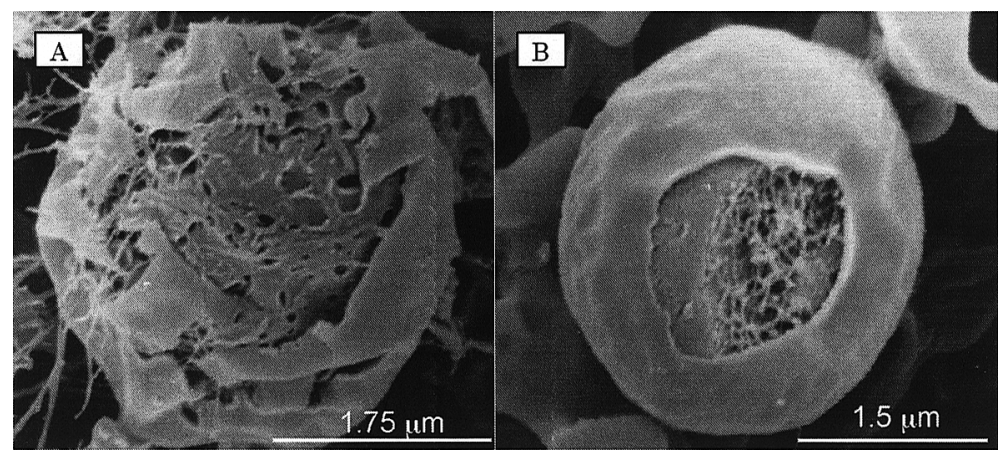

Fig. 2. Scanning Electron Micrographs of Lysed NIES-102 Cells with Volatile Terpenoids (A) perillaldehyde ( $2 \mathrm{mM}, 2 \mathrm{hr})$ and linalool (B) $(3 \mathrm{mM}, 9 \mathrm{hr})$.

the cell membrane (CM) structures. ${ }^{13,14)}$ Although the volatile cyanobacterial metabolites are physicochemically and structurally similar to those of the terpenoids produced by plants, the obtained results suggested that the modes of action of these two classes are different.

\section{Observation of the Morphological Change in Lysed Microcystis with Amino Acids Using SEM}

We isolated 83 actinomycete strains from the sediments of Lake Suwa, Nagano, Japan, and approximately half of the isolates were found to lyse cyanobacteria. One of them (S-9 strain), classified as Streptomyces phaeofaciens, grew well on the lawns of living cyanobacteria and rapidly lysed the cyanobacterial cells. It was found that this lytic activity was partially caused by secretion of an amino acid, Lys. ${ }^{15)}$ Although the anticyanobacterial activity of commercially available amino acids was investigated, the three basic amino acids, lysine, histidine and arginine, showed the similar activity. Interestingly, the absolute configurations of lysine, histidine and arginine, L, L, and $\mathrm{D}$, respectively, were essential for the activity, as their enantiometric isomers were inactive. Figure 3 shows the anticyanobacterial activity of the amino acids together with $\beta$-cyano-L-alanine at a concentration of $0.6 \mathrm{mM}$ against NIES-102. L-Histidine showed a different lytic behavior in which the absorbance at $665 \mathrm{~nm}$ increased after $100 \mathrm{hr}$. For the electron microscopic study, the lysed cells were sampled between 50 and $120 \mathrm{hr}$. Figure 4 shows typical scanning electron micrographs of the lysed cyanobacterial cells with the four amino acids. They showed common and characteristic morphological changes in which the cells initially swelled and then collapsed in the central area. The changes were completely different from

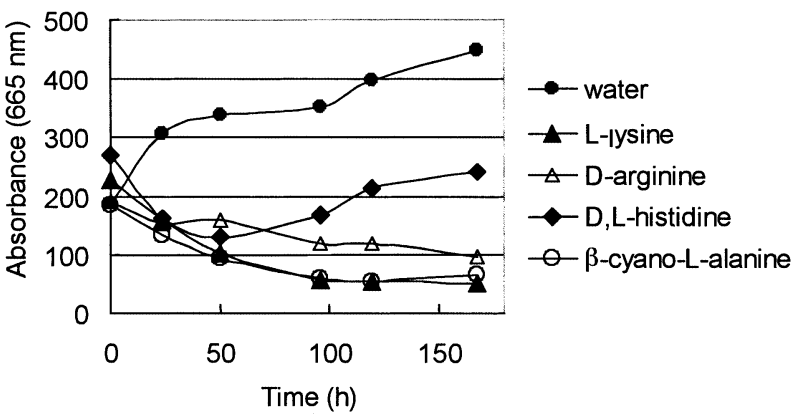

Fig. 3. Effect of Amino Acids at a Concentration of $0.6 \mathrm{mM}$ on Lysis of NIES-102

Water was used as the negative control. The absorbance was set at $665 \mathrm{~nm}$.

those of the volatile cyanobacterial metabolites and terpenoids mentioned above.

Although the anticyanobacterial activity of Lys has been studied by a few groups, ${ }^{15-17)}$ Takamura et al. discussed in detail the mode of action of Lys and related compounds. ${ }^{16)}$ They suggested that Lys has some effects on the biosynthesis of the cell wall (CW) peptidoglycan. The characteristic morphological changes mentioned above may correspond to this mode of action. They also reported that Lys lysed only the Microcystis strains and did not inhibit the Phormidium and Oscillatoria strains. ${ }^{16)} \beta$-Cyano-L-alanine was found to be active during the screening using Oscillatoria sp. ${ }^{18)}$ and also showed an anticyanoactivity against Microcsytis strains. These results suggested that the mode of action of the $\beta$-cyano-L-alanine was different from that of Lys, although the morphological changes caused by both amino acids seemed to be similar.

Observation of the Morphological Change in Lysed Microcystis with Antibiotics

Morphological studies have been performed us- 


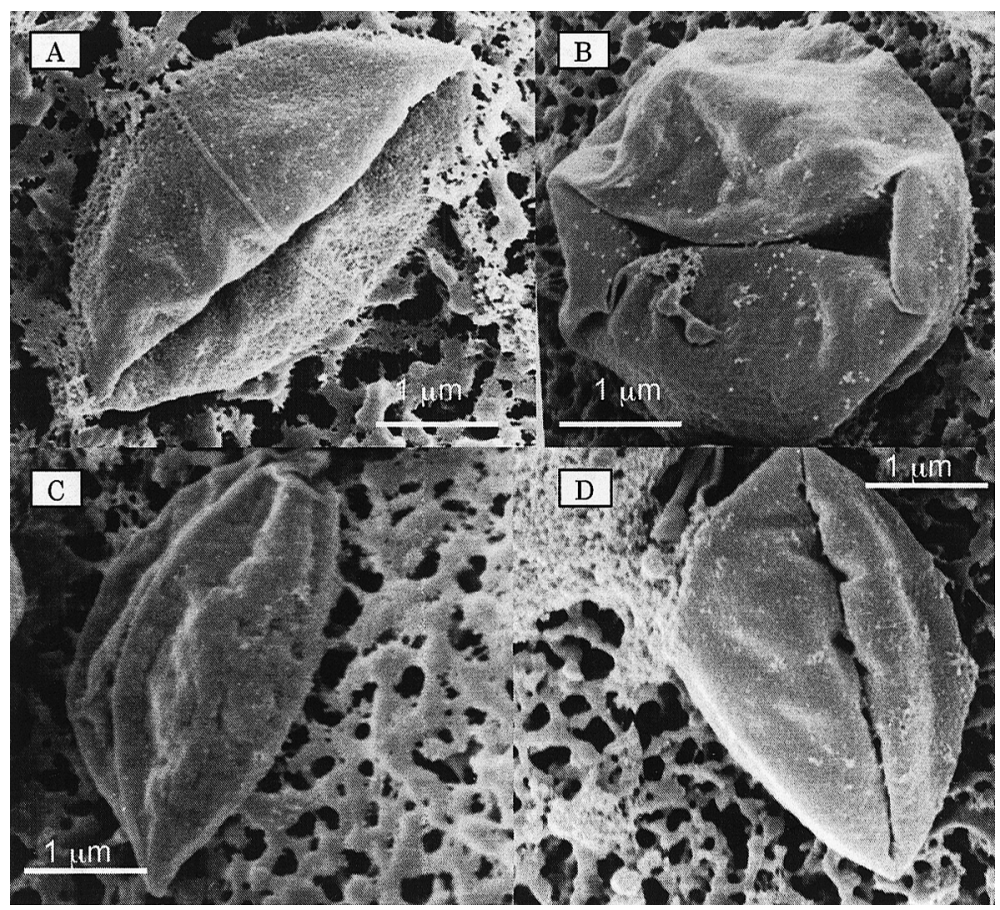

Fig. 4. Scanning Electron Micrographs of Lysed NIES-102 Cells with Amino Acids at a Concentration of $0.6 \mathrm{mM}$ (A) Lys (50 hr), (B) D-arginine (120 hr), (C) D,L-histidine (50 hr) and (D) $\beta$-cyano-L-alanine ( $96 \mathrm{hr}$ ).

ing electron microscopic techniques for the mode of action of the antibiotics. ${ }^{19-21)}$ Cyanobacteria are prokaryote and stain gram-negative as are the usual gram-negative bacteria. ${ }^{22)}$ Various antibiotics show the following modes of action against pathogenic bacteria: interrupting the normal interaction with the $\mathrm{CM}$; preventing the construction of bacterial CWs; interrupting the transcription and/or translation of microbial genes; and/or damaging the tertiary structure of the bacterial DNA. ${ }^{23)}$ Colistin, ceftazidime, gentamicin and ofloxacin are effective against gram-negative bacteria and have the respective modes of action mentioned above. Figure 5 demonstrates the anticyanobacterial activity of these four antibiotics against NIES 102. While colistin, gentamicin and ofloxacin showed a lytic activity, ceftazidime did not show such an activity even at a thousand times concentration of the measured MIC; $0.1 \mathrm{mM}$. Cephalosporin $\mathrm{C}$ was reported to be effective against Anabaena flosaquae. ${ }^{24)}$ The present result suggested that the activity was dependent on the genera of the cyanobacteria. Figure 6 shows the scanning electron micrographs of lysed cyanobacterial cells with these antibiotics. Colistin [Fig. 6(B)] and gentamicin [Fig. 6(C)] caused the cells to initially shrink and then became wrinkled; this lytic behavior was similar to that of $\beta$-cyclocitral. No characteristic mor-

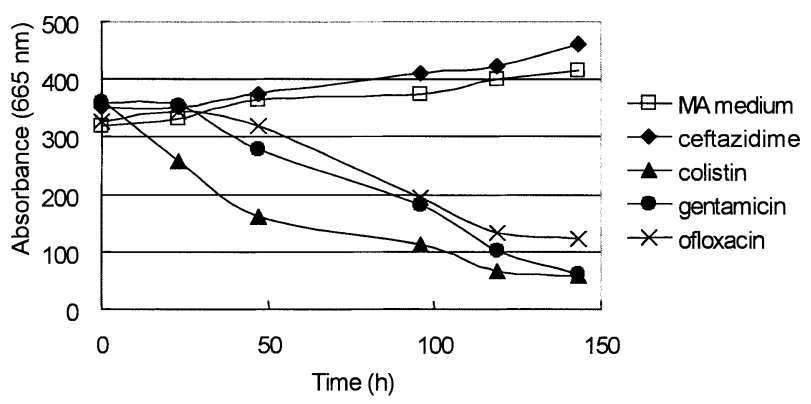

Fig. 5. Effect of Antibiotics, Ceftazidime $(0.2 \mathrm{mM})$, Colistin $(0.3 \mathrm{mM})$, Gentamicin Sulfate $(0.05 \mathrm{mM})$, and Ofloxacin $(0.1 \mathrm{mM})$ on Lysis of NIES-102

MA medium was used as the negative control. The absorbance was set at $665 \mathrm{~nm}$.

phological change was observed by ceftazidime and ofloxacin [Fig. 6(A) and (D)].

\section{Observation of the Intracellular Organs Using a TEM}

It is known that TEM is suitable for investigating the complex cytoplasmic organization of cyanobacteria. ${ }^{25)}$ In order to clarify the extreme difference in the morphological changes between the volatile cyanobacterial metabolites and basic amino acids, the TEM method was used. Figure 7 shows the transmission electron micrographs of the lysed cyanobacterial cells with $\beta$-cyclocitral 


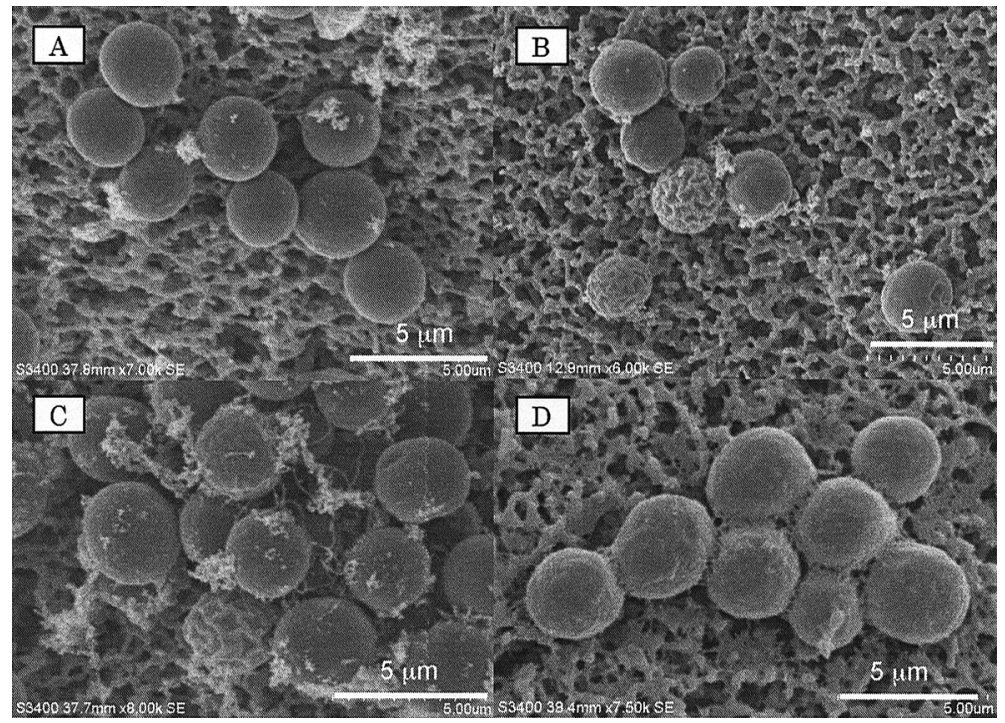

Fig. 6. Scanning Electron Micrographs of Lysed NIES-102 Cells with Antibiotics

(A) ceftazidime $(0.2 \mathrm{mM}, 33 \mathrm{hr})$, (B) colistin $(0.3 \mathrm{mM}, 8 \mathrm{hr})$, (C) gentamicin ( $0.05 \mathrm{mM}, 33 \mathrm{hr})$ and (D) ofloxacin $(0.1 \mathrm{mM}, 115 \mathrm{hr})$.

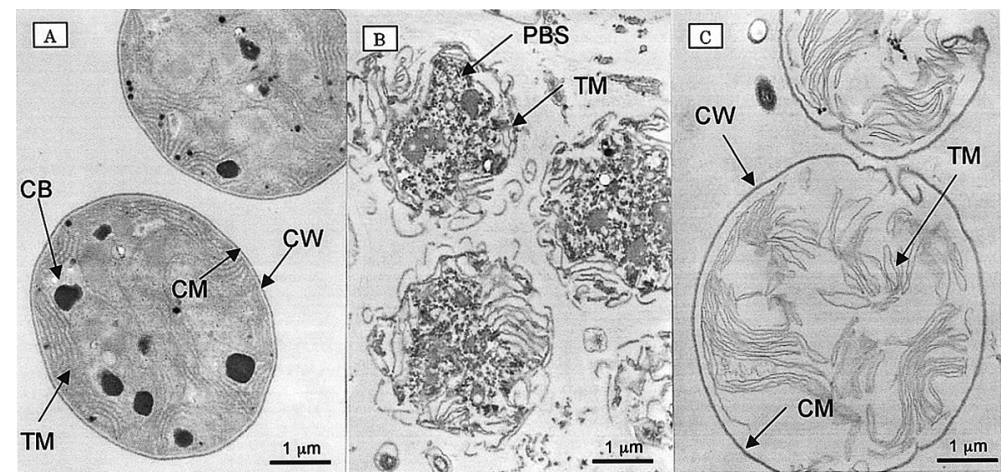

Fig. 7. Transmission Electron Micrographs of Lysed NIES-102 Cells with $\beta$-Cyclocitral and Lys

(A) Intact cell (0 hr), (B) $\beta$-cyclocitral (6.5 mM, $23 \mathrm{hr})$ and (C) Lys ( $0.6 \mathrm{mM}, 47 \mathrm{hr})$. Carboxysome (CB); Phycobilisome (PGS).

and Lys. When compared to the control [Fig. 7 (A)], the damage to the $\mathrm{CM}$ or $\mathrm{CW}$ on the surface was observed during lysis of the cyanobacteria with $\beta$ cyclocitral, but the thylakoid membrane (TM) with phycobilisome still existed at the center of the cell [Fig. 7 (B)]. The breakdown of the CM (W) at one point on the cyanobacterial cells lysed with Lys was observed and the TM remained, but the other structures in the cell disappeared [Fig. 7 (C)]. Yamamoto et al. reported the preliminary results for the lysis of cyanobacteria with Lys using TEM and showed that the sheath fiber and CWs of vegetative cells disappeared, but the TMs initially remained as a curled structure, although they subsequently disappeared completely. ${ }^{15)}$

The present study was performed in order to understand how the $\beta$-cyclocitral decomposes the cyanobacterial cell, and other anticyanobacterial agents were also investigated. The preliminary study using SEM demonstrated that there were three types of morphological changes in the cyanobacterial cells: Volatile compounds from cyanobacteria caused shrinking and then wrinkling; Terpenoids contacted directly and caused stripping; Basic amino acids caused swelling and then collapsing, when they were incubated with anticyanobacterial agents. In order to clarify the extreme difference in the morphological changes between the $\beta$ cyclocitral and Lys, TEM technology was used and a definite difference in the resulting photographs was obtained. Throughout the experiment using the antibiotics, it was found that the apparent morphological changes after lysis did not correspond to the mode of action. Very recently, the blue color 
formation was observed in a Japanese lake and a large amount of $\beta$-cyclocitral was simultaneously detected (unpublished results). Because it is considered that $\beta$-cyclocitral is critical for the regulation of cyanobacteria in a freshwater ecosystem, the obtained findings of this study will contribute to the elucidation of a mechanism for the lysis of cyanobacteria.

Acknowledgements We would like to thank the following scientists for their helpful discussions: Drs. Nobutaka Imamura (Ritsumeikan University), Sumio Nakamura (Kanagawa Dental College) and Tomohiko Watanuki (Tokyo Kasei University).

\section{REFERENCES}

1) Harada, K.-I., Kondo, F. and Lawton, L. (1999) Laboratory analysis of cyanotoxins. In Toxic Cyanobacteria in Water (Chorus, I. and Bartram, J. Eds.), E \& FN Spon, London, pp. 369-405.

2) Ortea, P. M., Allis, O., Healy, B. M., Lehane, M., Shuilleabháin, A. N., Furey, A. and James, K. J. (2004) Determination of toxic cyclic heptapeptides by liquid chromatography with detection using ultra-violet, protein phosphatase assay and tandem mass spectrometry, Chemosphere, 55, 1395-1402.

3) Sivonen, K. and Jones, G. J. (1999) Cyanobacterial toxins. In Toxic Cyanobacteria in Water (Chorus, I. and Bartram, J. Eds.), E \& FN Spon, London, pp. 41-111.

4) Kuiper-Goodman, T., Falconer, I. and Fitzgerald, J. (1999) Human health aspects. In Toxic Cyanobacteria in Water (Chorus, I. and Bartram, J. Eds.), E \& FN Spon, London, pp. 113-153.

5) Jochimsen, E. M., Carmichael, W. W., An, J. S., Cardo, D. M., Cookson, S. T., Holmes, C. E., Antunes, M. B., de Melo Filho, D. A., Lyra, T. M., Barreto, V. S., M. Azevedo, S. M. and Jarvis, W. R. (1998) Liver failure and death after exposure to microcystins at a hemodialysis center in Brazil, $N$. Engl. J. Med., 338, 873-878.

6) Pouria, S., de Andrade, A., Barbosa, J., Cavalcanti, R. L., Barreo, V. T., Ward, C. J., Preiser, W., Poon, G. K., Neild, G. H. and Codd, G. A. (1998) Fatal microcystin intoxication in haemodialysis unit in Caruaru, Brazil, Lancet, 352, 21-36.

7) Tsuji, K., Asakawa, M., Anzai, Y., Sumino, T. and Harada, K.-I. (2006) Degradation of microcystins using immobilized microorganism isolated in an eutrophic lake, Chemosphere, 65, 117-124.
8) Harada, K.-I., Tsuji, K., Ohta, A., Takayanagi, K., Tamaki, S., Suzuki, T., Ozaki, K., Ito E. and Fujii, K. (2007) Isolation of a lytic bacterium against cyanobacteria and its active compound, J. Res. Instit. Meijo Univ., 6, 17-28.

9) Ozaki, K., Ohta, A., Iwata, C., Horikawa, A., Tsuji, K., Ito, E., Ikai, Y. and Harada, K.-I. (2008) Lysis of cyanobacteria with volatile organic compounds, Chemosphere, 71, 1531-1538.

10) Fallon, R. D. and Brock, T. D. (1979) Lytic organisms and photoxidative effects: Influence on bluegreen algae (cyanobacteria) in lake Mendota, Winscosin, Appl. Environ. Microbiol., 38, 499-505.

11) Watanabe, M. F. (1996) Production of microcystins. In Toxic Microcystis (Watanabe, M. F., Harada, K.-I., Carmichael, W. W. and Fujiki, H. Eds.), CRC Press, Boca Raton, pp. 35-56.

12) Uchida, H., Kouchiwa, T., Watanabe, K., Kawasaki, A., Hodoki, Y., Otani, I., Yamamoto, Y., Suzuki, M. and Harada, K.-I. (1998) A coupled assay system for the lysis of cyanobacteria, Japanese Journal of Water Treatment Biology, 34, 67-75.

13) Cox, S. D., Mann, C. M., Markham, J. L., Bell, H. C., Gustafson, J. E., Warmington, J. R. and Wyllie, S. G. (2000) The mode of antimicrobial action of essential oil of Melaleuca alternifolia (tea tree oil), J. Appl. Microbiol., 88, 170-175.

14) Lambert, R. J., Skandamis, P. N., Coote, P. J. and Nychas, G. J. (2001) A study of the minimum inhibitory concentration and mode of action of oregano essential oil, thymol and carvacrol, J. Appl. Microbiol., 91, 453-462.

15) Yamamoto, Y., Kouchiwa, T., Hodoki, Y., Hotta, K., Uchida, H. and Harada, K.-I. (1998) Distribution and identification of actinomycetes lysing cyanobacteria in a eutrophic lake, Journal of Applied Phycology, 10, 391-397.

16) Takamura, Y., Yamada, T., Kimoto, A., Kanehama, N., Tanaka, T., Nakadaira, H. and Yagi, O. (2004) Growth inhibition of Microcystis cyanobacteria by L-Lysine and disappearance of natural Microcystis blooms with spraying, Microbes and Environments, 19, 31-39.

17) Kaya, K., Liu, Y. D., Shen, Y. W., Xiao, B. D. and Sano, T. (2005) Selective control of toxic Microcystis water blooms using lysine and malonic acid: an enclosure experiment, Environ. Toxicol., 20, 170178.

18) Yoshikawa, K., Adachi, K., Nishijima, M., Takadera, T., Tamaki, S., Harada, K.-I., Mochida, K. and Sano, H. (2000) $\beta$-Cyanoalanine production by marine bacteria on cyanide-free medium and its specific inhibitory activity toward cyanobacteria, Appl. 
Environ. Microbiol., 66, 718-722.

19) Takayama, K., Wang, L. and Merkal, R. S. (1973) Scanning electron microscopy of the H37Ra strain of Mycobacterium tuberculosis exposed to isoniazid, Antimicrob. Agents Chemother, 4, 62-65.

20) Henk, W. G., Todd, W. J., Enright, F. M. and Mitchell, P. S. (1995) The morphological effects of two antimicrobial peptides, hecate-1 and melittin, on Escherichia coli, Scanning Microsc., 9, 501-507.

21) Takata, T., Tabata, M., Tsuruoka, T. and Watabe, H. (2003) Activity of fosfomycin against Escherichia coli O157: H7-morphological changes and production of Shiga toxins, Jpn. J. Antibiot., 56, 691-696.

22) Stanier, R. Y. (1977) Cohen-Bazie. Phototrophic prokaryotes: the cyanobacteria, Annu. Rev. Microbiol., 31, 225-274.

23) Bannister, B. A., Beg, N. T. and Gillespie, S. H. (2000) Antimicrobial Chemotherapy. In Infectious Disease, Blackwell Science, London, pp. 51-80.

24) Redhead, K. and Wright, S. J. L. (1978) Isolation and properties of fungi that lyze blue-green algae, Appl. Environ. Microbiol., 962-969.

25) Van de Meene, A. M. L., Hohmann-Marriott, M. F., Vermaas, W. F. J. and Roberson, R. W. (2006) The three-dimensional structure of the cyanobacterium Synechocystis sp. PCC 6803, Arch. Microbiol., 184, 259-270. 